\title{
SMALL-SCALE SPATIAL OPTIMIZATION OF NATURAL GEOGRAPHIC REGIONS FOR BIODIVERSITY AND ECO- SUSTAINABILITY
}

\author{
SHANG, M. - CHEN, H. - CHEN, J. Y.* \\ College of Geography and Land Engineering, Yuxi Normal University, Yuxi 653100, China \\ *Corresponding author \\ e-mail: chenjingyi@yxnu.net; phone: +86-135-0940-5239 \\ (Received $7^{\text {th }}$ Jun 2019; accepted $10^{\text {th }}$ Oct 2019)
}

\begin{abstract}
The current scale of space division cannot effectively protect and manage the biodiversity in different natural geographic regions across China. To solve the problem, this paper optimizes natural geographic regions on a small scale based on the eco-sustainability and biodiversity in China, and prepares an optimized layout plan for China's ecological nature reserve system. The research results show that different natural geographic regions require different division scales, e.g. small-scale spatial layout is suitable for forest ecology and wild plants; the reduction in spatial scale has varied impacts on the protection of the different; the optimization of spatial scale is affected by vertical and horizontal gradients, e.g. the vegetation system is better protected in a region with small spatial scale; the small-scale spatial optimization of natural geographic regions makes the division of eco-environmental protection grids more effective; the regions with high biodiversity should be divided into denser grids to promote eco-sustainability. The research findings lay the theoretical basis for the planning of natural geographic regions and the maintenance of eco-diversity.
\end{abstract}

Keywords: eco-environment, biodiversity, sustainability, spatial layout, spatial optimization

\section{Introduction}

Today, the man-nature relationship gets increasingly strained, and the huge inputs in biodiversity protection have created an enormous social and economic burden on China. Protection for natural geographical areas has yielded an indistinctive result, especially for small and medium-sized ecological environments (Cochrane and Perrella, 2012). To study the best way to scientifically optimize the geographical regionalization grid, it is significant to effectively protect natural ecosystems and their biodiversity, and also improve it (Senator, 2017). The spatial optimization layout of China's natural geographical areas focuses primarily on the lists of protected species and important ecosystems, but lacks the integrated geographical regionalization on natural reserves, and never includes comprehensive and systematic protection of biodiversity (Maiano et al., 2006; Matchanov et al., 2016). Spatial optimization of natural geographic areas renders important basic data for regional biodiversity and eco-environmental protection and system construction of nature reserves. This lays a broad scientific foundation for developing regional biodiversity policies (Liu et al., 2014).

In recent years, scholars at home and abroad have made extensive studies on the spatial optimization of geographical areas, but the optimization methods vary according to different backgrounds, regionalization, bio-communities and other reference indicators. In response to the local geomorphological pattern, a small-scale spatial layout suitable for reserves has not yet been proposed (Sperry et al., 2016; Hübner and Schaal, 2017a). The principles of spatial optimization for natural geographic areas include relative consistency, the integration and the integrity. According to the regional 
geomorphology, the natural geographic areas can be divided into tier-1, 2, 3 and 4 spaces (Dyck and Willems, 2013). The regional spaces should be divided and optimized aiming at the construction of nature reserve systems with definite purposes, and the hierarchical regionalization system should overall be improved and more scientific (Hübner and Schaal, 2017b). Based on the sustainability of the ecological environment, this paper makes a spatial optimization for the natural geographical areas on a smallscale according to the biodiversity in China, and gives the optimal layout program for the ecological nature reserve system in China.

\section{Materials and methods}

Through the course of eco-environment protection, there are still many common problems. To reasonably protect the eco-environment, the best practice is to correctly evaluate current situation of the reserves and identify the existing key issues (Kaufmann and Banerjee, 2014). There are many types of small spaces included in natural geographic areas, including the natural reserves, wilderness reserves, the national parks, the natural monument museums, the habitat and species management reserves, the terrestrial and marine landscapes, etc. (Jiang and Liu, 2012). The spatial scale of natural geographical areas can be determined according to spatial acreage of the nature reserves. In general, the area greater than $10,000 \mathrm{~km}^{2}$ is called a large-scale space, and the area less than $100 \mathrm{~km}^{2}$ is called a small-scale space (Krasnov et al., 2015). According to the incomplete statistics, China's nature reserves cover an area of more than $106 \mathrm{~km}^{2}$, and the layout of most spaces are statistically designed as required by the provinces as the large scales, thus leading the statistical species to averaging (Jiang et al., 2013).

Using statistical survey method, according to data from the Bureau of Land and Resources, currently, there are 2392 nature reserves having been divided in China, among which, there are more than 400 small-scale ones. As shown in Figure 1, different types of national nature reserves as percentage of the total areas are figured out, where the desert ecology ranks the first, followed by the wild animals and inland wetlands. The desert ecology is suitable for large-scale spatial layout in natural geographical areas, and for the forest ecology and wild plants, they are suitable for small-scale spatial layout. Figure 2 illustrates the number of different types of the national nature reserves. It is obvious that there is a great difference in the construction layout in different times between various nature reserves. There are even more layouts for the forest ecology due to the fact that forest ecology is mostly divided on a small scale.

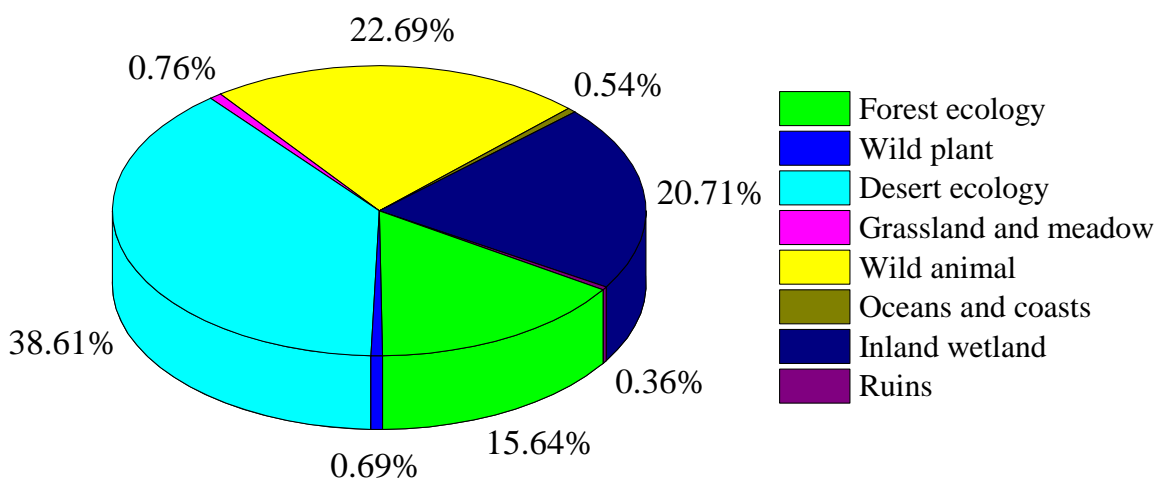

Figure 1. Area ratio of different types of national nature reserves 


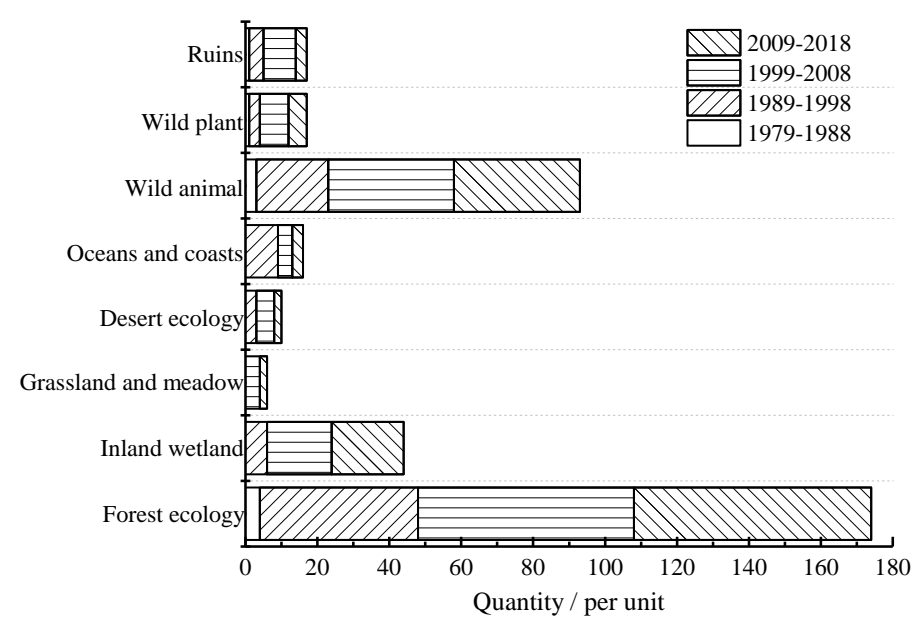

Figure 2. Number of national nature reserves of different types

\section{Results}

\section{Small-scale spatial division for regional system}

To divide the small-scale spaces in natural geographical areas, it is conducive to safeguard the ecosystems, rare and endangered animals and plants, as well as the sites and relics. According to the existing areas as divided, the number of national nature reserves in different natural geographical areas and the corresponding upland areas are not directly proportional to each other, and there are disparities in the scale division between the natural geographical areas. For the number and the area of small-scale spaces in the nature reserves, see Figure 3. It is obvious that the number of small-scale spaces in China increases year by year, but their mean area calculated by the ratio of the area to the number gradually decreases.

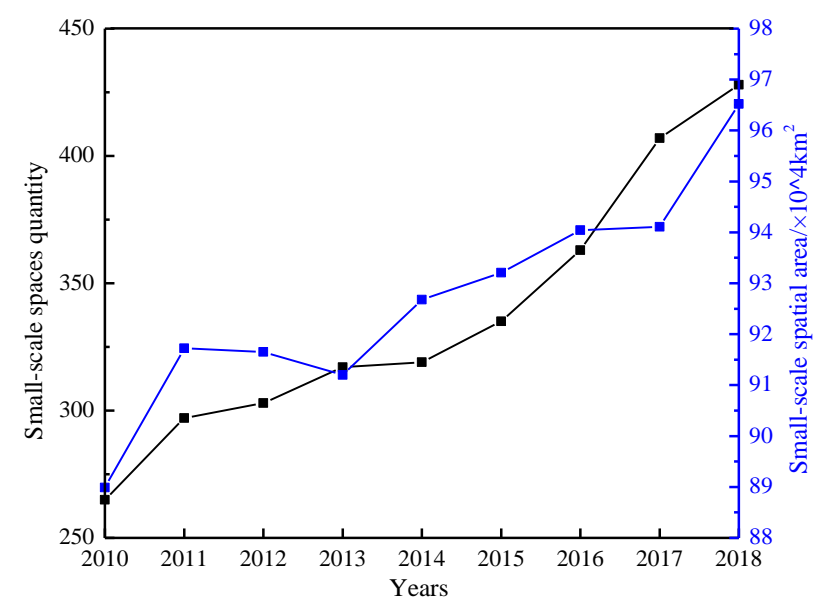

Figure 3. Quantity and area of small-scale space in nature reserves

The small-scale spaces as percentage of the natural geographical areas at different protection ratios are shown in Figure 4, more than $30 \%$ of them are protected at less than 5\%. Among them, there are the maximum small-scale spaces in the unprotected natural geographic areas in the northwest warm temperate zone, exceeding $70 \%$ of the 
total. Further, except for the Qinghai-Tibet Plateau, a natural geographical area, the protective area of small-scale spaces in other geographical areas is generally $3 \%$ lower than that of other land areas. The total small-scale spaces as percentage of the natural geographical areas at different protection ratios are shown in Figure 5. In the east and south China, the small-scale spaces as percentage of the natural geographical areas at the protection ratio below $5 \%$ is the maximum, followed by those in the north China and in the northwest China. As the scale spaces diminish, the effective protection in different natural geographic areas varies from unit to unit.

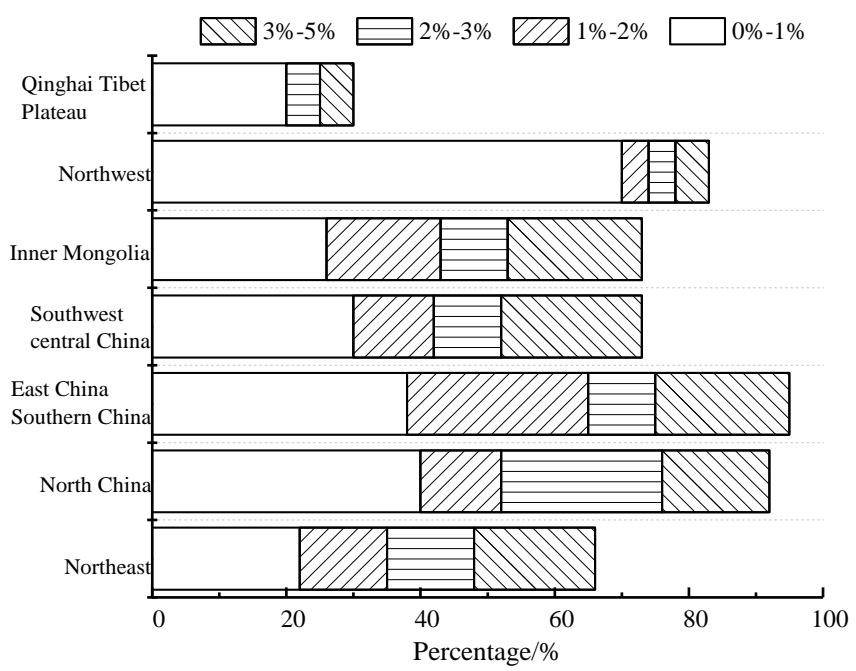

Figure 4. The proportion of the total number of small-scale space in different conservation proportions of natural geographical regions

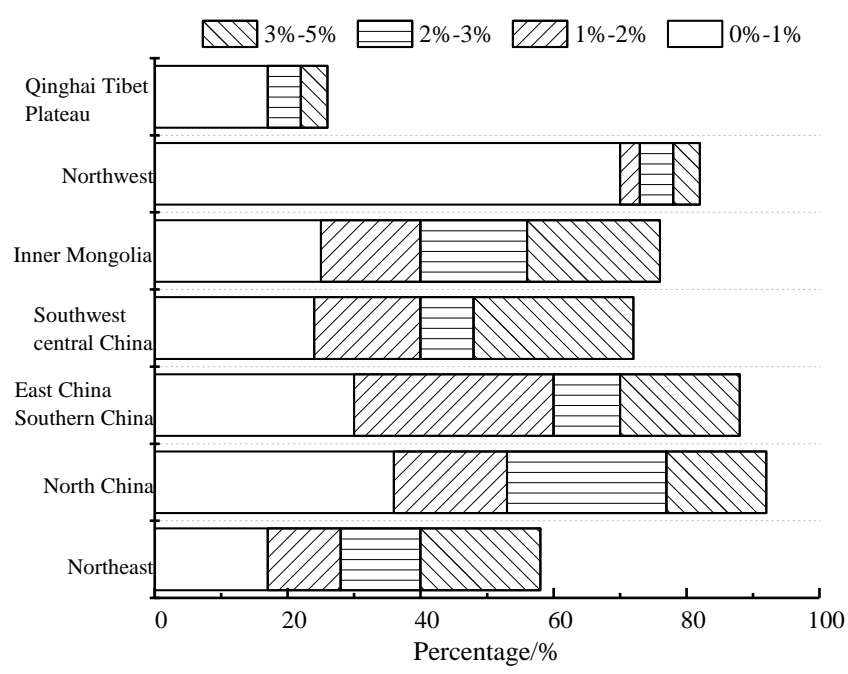

Figure 5. The proportion of the total area of small-scale space in the natural geographical regions with different protection ratios

\section{Analysis of vegetation ecosystem protection potency}

Investigation research shows that the vegetation system is suitable for dividing smallscale spaces in the natural geographical areas. The regional biodiversity may be subject 
to the spatial layout of vegetation. It is impossible to make up for the gap in the conservation of existing reserves by evaluating biodiversity distribution data with divided scale spaces. The vegetation ecosystem may be subjected to the topography, altitude and climatic environment. Vegetation distribution pattern and its conservation have a significant impact on global biodiversity and the protection of natural ecosystems. Vegetation systems in small-scale spatial areas will be protected at a higher rate. In different natural geographical areas, some reserves have a concentrated layout, and the coverage of upland areas as they did in different areas varies greatly. The current situation of small-scale spaces as percentage of the total conserved vegetation systems is illustrated in Figure 6. As we can see, more than $60 \%$ of the vegetation systems are conserved at a rate of less than $5 \%$.

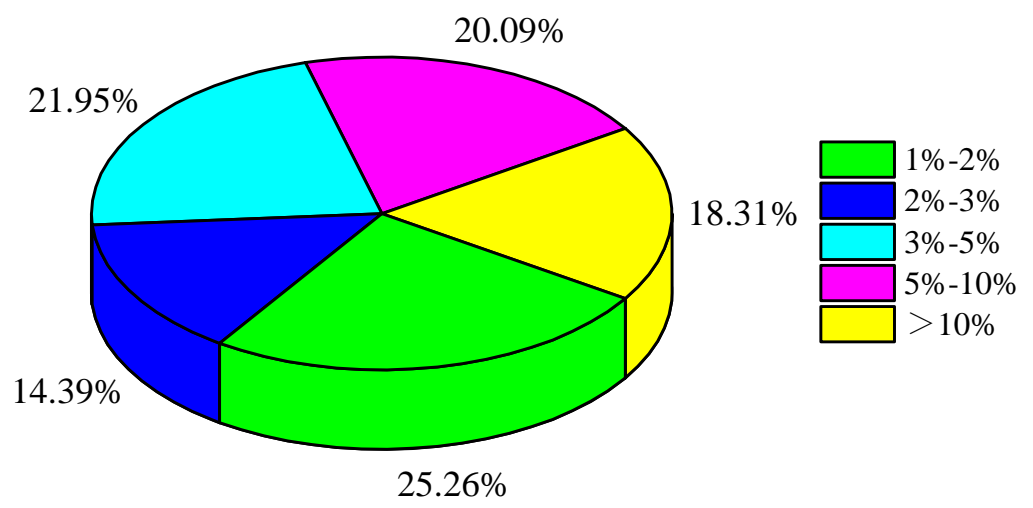

Figure 6. Current status of small-scale spatial conservation proportion of vegetation system

Figure 7 illustrates the small-scale spaces as percentage of natural geographical areas at different altitudes. As can be seen, the small-scale spaces are mainly distributed at low altitude $(<200 \mathrm{~m})$ and $1000-3000 \mathrm{~m}$ altitude in North China (Fig. 7a); at 1000$3000 \mathrm{~m}$ altitude in the southwest of central China (Fig. 7b); and relatively uniform in the northeast areas (Fig. 7c), presenting the tendency to decrease with the increase of altitude height. The small-scale spaces of the natural geographical area in the QinghaiTibet Plateau (Fig. $7 d$ ) are all centralized in the high altitude areas $(>3000 \mathrm{~m})$.

\section{Discussion}

\section{Evaluation on biodiversity conservation value by small-scale spatial optimization}

The small-scale space divided in the natural geographical areas is an important form for biodiversity conservation. The priority and biodiversity of small-scale spaces particularly value the typicality and non-substitutability of species and their habitats. There are some main evaluation indicators for biodiversity conservation value, including diversity, representative, scarcity, natural type, area suitability and vulnerability, etc. Great attention should be paid to the diversity of habitat types, while in different scale spaces, the evaluation indicators for biodiversity conservation values vary, but they all focus on the rare and endangered features, protection classes and geographical distribution tendencies of the species. For example, in Jilin Changbai Mountain, there are large chunks of rare animals and plants in the natural geographical areas, so that its diversity protection value is high. 


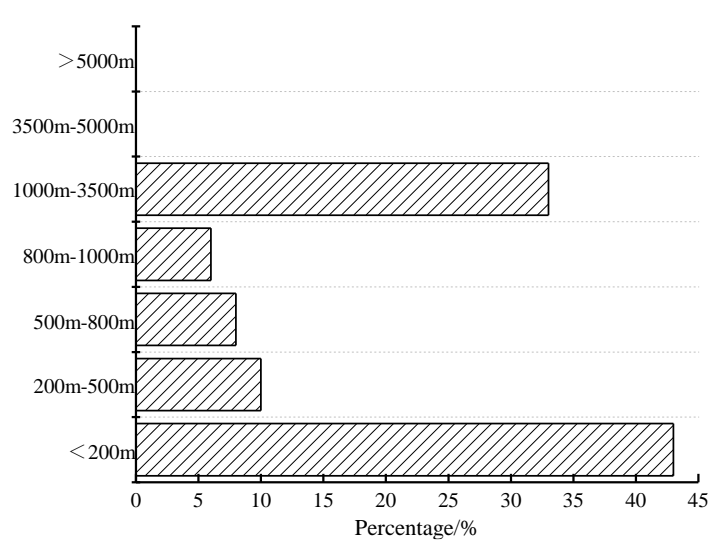

(a) North China region

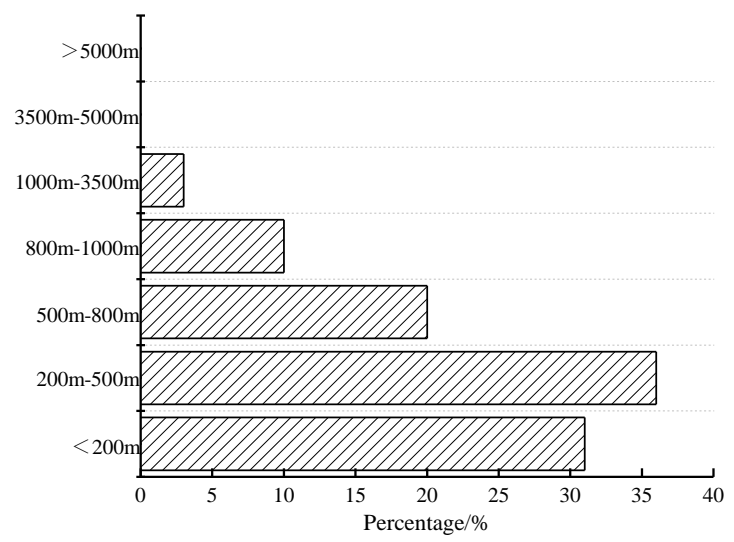

(c) Northeast region

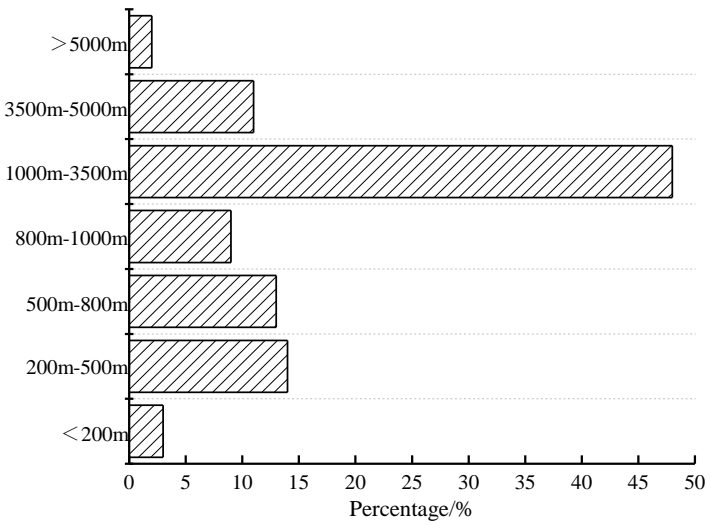

(b) Central South China

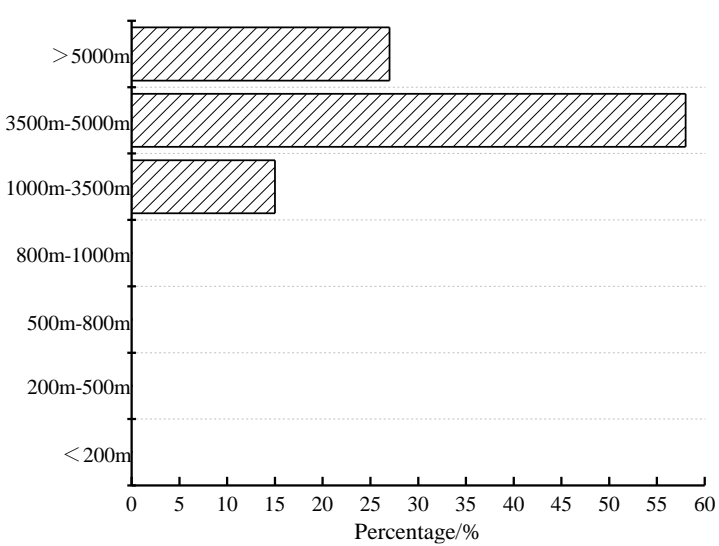

(d) Qinghai-Tibet Plateau region

Figure 7. Proportion of small-scale space in natural geographical regions at different altitudes

To evaluate how the biodiversity conservation values are susceptible to small-scale spatial optimization, 39 small-scale spaces in the northeastern areas are chosen for study, and different attributes of individual species in the scale space grid are assigned the values at different levels. Those scale spaces with the highest protection value index mainly concentrate in the deciduous broad-leaved forest area of the Taihang Mountain, while those with the maximum protection value index of wild plant diversity fall in the cultivated vegetation and wetland area of Haihe Plain.

\section{Optimized layout plan for China's ecological nature reserve system}

On the whole, China has divided the natural geographical areas, but the optimization for small-scale spaces is a complex process involving multiple protection targets and strategies, habitat quality. The existing large-scale space is divided into several smallscale spaces to establish a more effective eco-environmental protection network. It is preferable to divide the area with high biodiversity conservation value into a spatial grid for small-scales, or connect several reserves near each other into a reserve network, this is an important strategy for realizing the natural conservation. Specifically speaking, it is to set up eco-environmental lag zones, and divide them into two categories according to the optimization difficulty: the barely-coordinated ecological optimization zone and the nearly-uncoordinated ecological optimization zone. The land types that need to be renovated are adjusted to forest land, garden land, wetland and other ecological 
environments so as to improve the land types that can produce positive effects. According to the existing natural geographical division grid and the preferred biodiversity reserves, the scale space optimization program is designed based on the layout principle of building the areas with low diversity conservation value into the large-scale spaces, and preferentially optimizing the national or international important nature geographical areas into small-scale spaces. In the key natural areas, the species should be highly protected. Those mall-scale spaces with higher conservation values can be preferentially promoted to the national nature reserves.

Figure 8 shows the comparison of the national nature reserves at the protection ratios after small-scale spaces are optimized. As we can see, the bio-conservation coverage in natural geographical areas increases after the spatial optimization layout for small-scale spaces. Figure 9 shows the optimal composition of small-scale spaces in natural geographic areas. The small-scale spaces in the natural geographical areas are mainly composed of forest ecology, inland wetlands and wild animals. Small-scale spatial layout can effectively fulfill the protection and management targets to more quickly make management measures and tools.

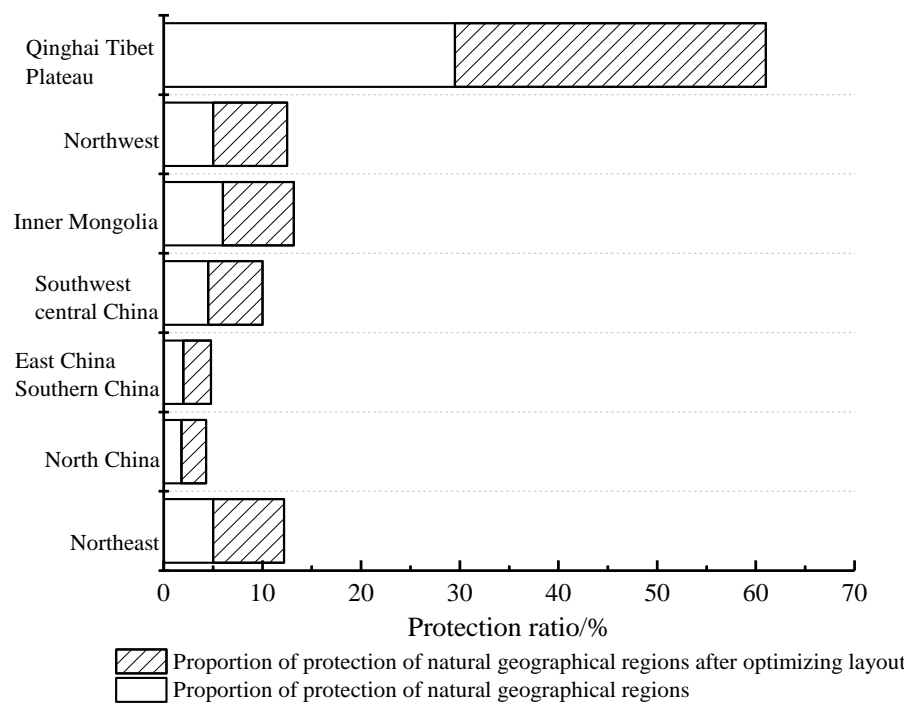

Figure 8. Proportion of national nature reserves after small-scale space optimization

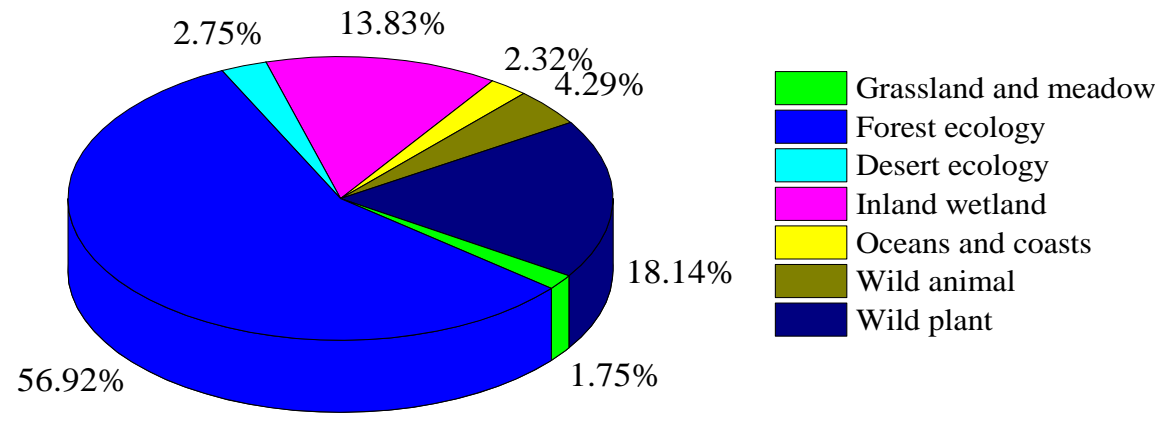

Figure 9. Small-scale spatial optimization composition of natural geographical regions 


\section{Conclusion}

Based on the sustainability of the ecological environment, this paper optimizes the small-scale spaces in the natural geographical areas in line with the biodiversity of China. In doing so, the optimal layout program is given for the ecological nature reserve system in China. Here come specific conclusions:

- The number of small-scale spaces in China increases year by year, but the mean area of small-scale spaces gradually decreases. In the east and south China, the small-scale spaces as percentage of the total at a protection ratio of less than $5 \%$ in the natural geographical area $5 \%$ is the highest, followed by those in north China and in north-west region.

- The vegetation system in the small-scale spaces will be protected at a higher ratio. In different natural geographical areas, some protected areas have a concentrated spatial layout, quite different from coverage ratio of the land area in different zones.

- The existing large-scale space is divided into several small-scale ones to establish a more effective eco-environmental protection network. It is preferable to divide the area with high biodiversity conservation value into a small-scale spatial grid, or connect the reserves near each other into a reserve network. This is an important strategy for realizing ecological environmental protection and species diversity.

- This paper analyzed the advantages of spatial optimization for ecosystem development based on actual data. With the sustainable and coordinated development of ecological environment reserves as the principle, it optimized the allocation of ecological spaces and provided a reference for natural geography and land use.

Acknowledgements. This research has been financed by Educational Science Planning Project in Yunnan Province in 2018 "Practical Research on Constructing School-based Course of Innovative GIS Experiment Based on Skills Contests and Teaching” (GJZ171813).

\section{REFERENCES}

[1] Cochrane, C., Perrella, A. (2012): Regions, regionalism and regional differences in canada. - Canadian Journal of Political Science 45(4): 829-853.

[2] Dyck, V. J., Willems, P. (2013): Probabilistic flood risk assessment over large geographical regions. - Water Resources Research 49(6): 3330-3344.

[3] Hübner, A., Schaal, K. (2017a): An integrated assortment and shelf-space optimization model with demand substitution and space-elasticity effects. - European Journal of Operational Research 261(1): 302-316.

[4] Hübner, A., Schaal, K. (2017b): Effect of replenishment and backroom on retail shelfspace planning. - Business Research 10(1): 123-156.

[5] Jiang, B., Liu, X. (2012): Scaling of geographic space from the perspective of city and field blocks and using volunteered geographic information. - International Journal of Geographical Information Science 26(2): 215-229.

[6] Jiang, B., Liu, X., Jia, T. (2013): Scaling of geographic space as a universal rule for map generalization. - Annals of the Association of American Geographers 103(4): 844-855.

[7] Kaufmann, R. K., Banerjee, S. (2014): A unified world oil market: regions in physical, economic, geographic, and political space. - Energy Policy 74: 235-242. 
[8] Krasnov, B. R., Shenbrot, G. I., Khokhlova, I. S., Stanko, M., Morand, S., Mouillot, D. (2015): Assembly rules of ectoparasite communities across scales: combining patterns of abiotic factors, host composition, geographic space, phylogeny and traits. - Ecography 38(2): 184-197.

[9] Liu, X. C., Zhang, J. Q., Li, X. Z. (2014): Geographical information system-based assessment of ecological security in Changbai Mountain region. - Journal of Mountain Science 11(1): 86-97.

[10] Maiano, C., Ninot, G., Stephan, Y., Morin, A. J. S., Florent, J.-F., Vallée, P. (2006): Geographic region effects on adolescent physical self: an exploratory study. International Journal of Psychology 41(2): 73-84.

[11] Matchanov, M., Teodoro, A., Schroder, C. (2016): Criterion definition for the identification of physical-geographical boundaries of Khorezm oasis through remotely sensed data. - Environmental Monitoring and Assessment 188(1): 35.

[12] Senator, S. A. (2017): Flora diversity of physical-geographical regions and a scheme of floristic zoning of middle Povolzh'e. - Biology Bulletin 44(10): 1208-1214.

[13] Sperry, M. M., Telesford, Q. K., Klimm, F., Bassett, D. S. (2016): Rentian scaling for the measurement of optimal embedding of complex networks into physical space. - Journal of Complex Networks 5(2): 199-218. 